\title{
PRODUÇÃO DOS TAROS 'CHINÊS' E 'MACAQUINHO' EM FUNÇÃO DE DIFERENTES DOSES DE URÉIA
}

\author{
Yield of 'Chinês' and 'Macaquinho' taros as a function of different doses of urea
}

\author{
Néstor A. Heredia Zárate ${ }^{1}$, Maria do Carmo Vieira ${ }^{1}$, Rafael Bratti ${ }^{2}$
}

\begin{abstract}
RESUMO
Conduziu-se este trabalho com o objetivo de avaliar a produção e a receita de dois clones de taro cultivados sob diferentes doses de uréia no solo. O trabalho foi desenvolvido em área do Horto de Plantas Medicinais, do Núcleo Experimental de Ciências Agrárias, da Universidade Federal de Mato Grosso do Sul, em Dourados-MS, no período de 5-9-2002 a 25-4-2003. Foram avaliados os clones de taro Macaquinho e Chinês, sob incorporação ao solo de $0,60,120,180$ e $240 \mathrm{~kg} \mathrm{ha}^{-1}$ de uréia $(45 \%$ de N). Os tratamentos foram arranjados como fatorial 2 x 5 , no delineamento experimental de blocos casualizados, com três repetições. O plantio foi com rizomas-filho inteiros, sob população de 73.260 plantas ha ${ }^{-1}$. A colheita das plantas do 'Macaquinho' foi efetuada aos 189 dias após o plantio, e as do 'Chinês', aos 232 dias, quando mais de $70 \%$ da parte aérea das plantas apresentavam sintomas de senescência. As plantas do taro 'Macaquinho' produziram 41,89 $\mathrm{t} \mathrm{ha}^{-1}$ de rizomas totais e $10,49 \mathrm{t} \mathrm{ha}^{-1} \mathrm{de} \mathrm{ri}^{-}$ zomas-mãe-RM, o que correspondeu, respectivamente, a 3,06 (7,88\%) e 3,15 t ha ${ }^{-1}(42,92 \%)$ a mais do que do 'Chinês', e com ciclo vegetativo de 43 dias a menos. As maiores produções de massa fresca de rizomas-filho-RF comerciais foram com a adição ao solo de $240\left(31,77 \mathrm{t} \mathrm{ha}^{-1}\right)$ e $180\left(19,90 \mathrm{t} \mathrm{ha}^{-1}\right) \mathrm{kg} \mathrm{ha}^{-1}$ de uréia. A produção de massa seca de rizomas totais foi dependente da interação clones e adubação com uréia, e as doses influenciaram significativamente na produção das plantas do 'Macaquinho'

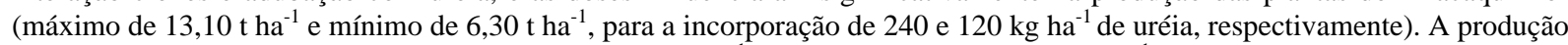
de massa seca de RM foi maior no 'Macaquinho' $\left(2,26 \mathrm{tha}^{-1}\right)$ e menor no 'Chinês' $\left(1,95 \mathrm{t} \mathrm{ha}^{-1}\right)$. A massa seca dos RF comerciais dependeu significativamente das doses de uréia, sendo maior com a incorporação de $240 \mathrm{~kg} \mathrm{ha}^{-1}$ de uréia $\left(7,05 \mathrm{t}^{-1}\right)$ e menor com $60 \mathrm{~kg} \mathrm{ha}^{-1}$ de uréia $\left(3,91 \mathrm{t} \mathrm{ha}^{-1}\right)$. As maiores receitas e lucros calculados foram para o uso de $240 \mathrm{~kg} \mathrm{ha}^{-1}$ de uréia, nos dois clones. O uso das menores doses de uréia foi economicamente negativo para as plantas do 'Macaquinho', inclusive em relação à não-adição de uréia.
\end{abstract}

Termos para indexação: Colocasia esculenta, Araceae, clones, adubações, produtividade, lucro.

\section{ABSTRACT}

The objective of this work was to evaluate yield and income of two taro clones cultivated under different doses of urea to the soil. The work was carried out at medicinal plant garden of the Agrarian Science Experimental Center of the Federal University of Mato Grosso do Sul, in Dourados - MS, in the period of September $5^{\text {th }}, 2002$, to April 25 ${ }^{\text {th }}$, 2003. 'Macaquinho' and 'Chinês' taro clones were evaluated under incorporation to the soil of $0 ; 60 ; 120 ; 180$ and $240 \mathrm{~kg} \mathrm{ha}^{-1}$ of urea (45\% of N). Treatments were arranged as 2 × 5 factorial scheme in a randomized block design with three replications. Planting was done with whole cormels under populations of 73,260 plants ha ${ }^{-1}$. Harvest of 'Macaquinho' plants was done at 189 days after planting and harvest of 'Chines" at 232 days, when more than $70 \%$ of aerial parts of plants showed senescence symptoms. Plants of 'Macaquinho' taro produced $41.89 \mathrm{t} \mathrm{ha}^{-1}$ of total rhizomes and $10.49 \mathrm{t} \mathrm{ha}^{-1}$ of corms - RM, which corresponded to 3.06 (7.88\%) and $3.15(42.92 \%)$, respectively, more than 'Chines" did, and with vegetative cycle of 43 days less than this one. Highest yields of commercial cormel fresh mass were with addition to the soil of $240\left(31.77 \mathrm{t} \mathrm{ha}^{-1}\right)$ and $180\left(19.90 \mathrm{t} \mathrm{ha}^{-1}\right) \mathrm{kg} \mathrm{ha}^{-1}$ of urea. Dried mass yield of total rhizomes was dependent on clones/fertilization with urea interaction, in which doses influenced significantly on yield of 'Macaquinho' plants (maximum of $13.10 \mathrm{t} \mathrm{ha}^{-1}$ and minimum of $6.30 \mathrm{t} \mathrm{ha}^{-1}$, for incorporation of 240 and $120 \mathrm{~kg} \mathrm{ha}^{-1}$ of urea, respectively). RM dried mass yield was higher for 'Macaquinho' $\left(2.26 \mathrm{t} \mathrm{ha}^{-1}\right)$ and smaller for 'Chinês' $\left(1.95 \mathrm{t} \mathrm{ha}^{-1}\right)$. Commercial RF dried mass depended significantly on urea doses, which was higher with the incorporation of $240 \mathrm{~kg} \mathrm{ha}^{-1}$ of urea $\left(7.05 \mathrm{t} \mathrm{ha}^{-1}\right)$ and smaller with $60 \mathrm{~kg} \mathrm{ha}^{-1}$ of urea $\left(3.91 \mathrm{t} \mathrm{ha}^{-1}\right)$. The greatest calculated incomes and profits were for the use of 240 $\mathrm{kg} \mathrm{ha}^{-1}$ of urea for both two clones. The use of smaller urea doses was economically negative for 'Macaquinho' plants including in relation to no addition of urea.

Index terms: Colocasia esculenta, Araceae, clones, fertilization, productivity, profit.

(Recebido para publicação em 11 de setembro de 2003 e aprovado em 15 de outubro de 2003) 


\section{INTRODUÇÃO}

O Estado de Mato Grosso do Sul ainda não tem tradição no cultivo de hortaliças, praticando principalmente o monocultivo soja e milho, além da criação de gado de corte. Nos últimos anos, vêm aumentando as áreas de cultivo de hortaliças nos arredores das maiores cidades do Estado, o que possibilita a venda do produto diretamente ao consumidor (VIEIRA, 1995). Atualmente a quantidade disponível de taro nos mercados locais e o número de horticultores dedicados à sua exploração é pequeno, por falta de tradição no consumo pela população local e pela falta de alternativa de uso dos produtos principais (rizomas-filho comerciais) e dos seus resíduos amídicos, composto por rizomas-mãe e rizomasfilho não-comerciais (HEREDIA ZÁRATE e YAMAGUTI, 1994).

Os rizomas de taro, por suas características nutricionais, têm possibilidades de uso humano, sob diferentes formas de preparo, podendo substituir, total ou parcialmente, a batatinha, a mandioca, o milho, o trigo e outras espécies amídicas (ABRAMO, 1990; CARÁ..., 1994). Também podem ser utilizados na alimentação animal, especialmente para frangos de corte (HEREDIA ZÁRATE et al., 2001). Por isso, o taro pode tornar-se, para os agricultores sulmatogrosenses, uma nova fonte de trabalho e de renda; para os consumidores, uma alternativa para a dieta alimentar; para os industriais, uma nova linha produtiva; para os exportadores, uma nova fonte comercial, e para o Brasil, novas fontes de emprego e de divisas.

A produtividade das plantas de taro é grandemente variável por causa do desconhecimento das características genotípicas das diferentes cultivares, assim como pelas diferenças nas práticas de plantio (HEREDIA ZÁRATE e YAMAGUTI, 1994). Por meio de uma série de restrições, é possível inferir que a produção de uma cultura é função dos elementos químicos essenciais existentes no solo ou de um elemento em particular. Isso significa que, quantitativamente, a produção, medida em $\mathrm{t} \mathrm{ha}^{-1}$, é função de um elemento essencial qualquer, medido em $\mathrm{kg} \mathrm{ha}^{-1}$. Dessa maneira, haverá uma quantidade total do elemento que provocará a produção máxima do vegetal, sob determinada situação. Se for possível conhecer a quantidade total necessária e a proveniente do solo, da água e do ar, será possível calcular a quantidade que deverá ser suplementada com adubo (KIEHL, 1993; LARCHER, 2000).

Os processos da nutrição das plantas são relacionados com a aquisição dos elementos nutritivos e com suas funções na vida delas (EPSTEIN, 1975; LARCHER, 2000). O nitrogênio, que é absorvido na forma de catiônio amoniacal $\left(\mathrm{NH}_{4}^{+}\right)$e principalmente na forma do aniônio nitrato $\left(\mathrm{NO}_{3}^{-}\right)$, é constituinte de proteínas (aproximadamente $18 \%$ ), aminoaçúcares, purinas e pirimidinas, alcalóides, coenzimas, vitaminas e pigmentos (CAMPORA, 1994; LARCHER, 2000). A absorção de $\mathrm{NH}_{4}{ }^{+}$, que pode servir imediatamente para a síntese de aminoácidos e outros compostos que contêm $\mathrm{N}$ reduzido, causa grande demanda de esqueletos carbônicos e, se a fotossíntese não for suficiente, pode causar exaustão nos carboidratos. A assimilação é rápida, de modo que não há muito acúmulo de amônio nos tecidos. $\mathrm{O} \mathrm{NO}_{3}{ }^{-}$tem que ser reduzido antes da sua assimilação e a demanda imediata por carboidratos é menor do que no caso do amônio e, por isso, pode haver acúmulo apreciável de ácidos orgânicos (EPSTEIN, 1975; MALAVOLTA et al., 1989; FERREIRA et al., 1993; KIEHL, 1993; LARCHER, 2000).

No solo, o nitrogênio ocorre, principalmente, na forma orgânica (95\% de $\mathrm{N}$ total), estando sua disponibilidade para as plantas associada à atividade dos microorganismos que sintetizam e decompõem a matéria orgânica (FORNASIERI FILHO, 1992). O clima, o estágio de crescimento, a espécie/cultivar e a disponibilidade de outros nutrientes têm implicações nos ajustamentos metabólicos à absorção dos iônios amoniacal e nítrico. A menos que o meio (solo) seja tamponado ou constantemente renovado, a absorção do amônio causa abaixamento do $\mathrm{pH}$ e a do nitrato aumenta o $\mathrm{pH}$ (FERREIRA et al., 1993; LARCHER, 2000). A fertilização das culturas, no entanto, não é a única ou a melhor prática para o aumento da produtividade. Práticas como a escolha da cultivar para as condições prevalecentes na área, forma de condução da cultura e sistema de irrigação podem alterar a produtividade com tanta eficiência ou mais do que com a adubação. Por isso, em Mato Grosso do Sul, está sendo estudado e incentivado o cultivo dos clones Japonês, Branco, Macaquinho, Chinês e Cem/Um, tanto em solos "sempre úmidos" (HEREDIA ZÁRATE e YAMAGUTI, 1994) como em condições do pantanal (HEREDIA ZÁRATE, 1995). Observam-se na literatura citações de altas produtividades de taro no Havaí, nas faixas de 35,7 a 71,4 $\mathrm{t} \mathrm{ha}^{-1}$ nas terras baixas e de 14,3 a $23,8 \mathrm{t} \mathrm{ha}^{-1}$ nas terras altas. Entretanto, encontraram-se variações de $4,8 \mathrm{t} \mathrm{ha}^{-1}$ em Trinidade até 32,4 $\mathrm{t} \mathrm{ha}^{-1}$ na Índia (PLUCKNETT et al., 1970). No Brasil, são citadas produções médias de rizomas-filhos de taro entre $12 \mathrm{t} \mathrm{ha}^{-1}$ no Rio de Janeiro (PEREIRA, 1994) e $20 \mathrm{t} \mathrm{ha}^{-1}$ na região de Inhapim-MG (SANTOS, 1994). 
Considerando que na literatura há poucos relatos sobre uso de adubos químicos, especialmente sobre os nitrogenados na cultura do taro (PUIATTI, 1990), objetivouse com este trabalho conhecer o rendimento de massas fresca e seca de partes amídicas de plantas de dois clones de taro cultivadas sob adição ao solo de cinco doses de uréia.

\section{MATERIAL E MÉTODOS}

O trabalho foi desenvolvido em área do Horto de Plantas Medicinais, do Núcleo Experimental de Ciências Agrárias, da Universidade Federal de Mato Grosso do Sul, em Dourados-MS, no período de 5-92002 a 25-4-2003. As características químicas do solo, nos três blocos do experimento, são apresentadas na Tabela 1. O município de Dourados situa-se em latitude de $22^{\circ} 13^{\prime} 16^{\prime \prime}$, longitude de $54^{\circ} 17^{\prime} 01^{\prime \prime} \mathrm{W}$ e altitude de $430 \mathrm{~m}$. O clima da região, segundo a classificação de Köppen (MATO GROSSO DO SUL, 1990), é Mesotérmico Úmido, do tipo Cwa, com temperaturas e precipitações médias anuais que variam de $20^{\circ}$ a $24^{\circ} \mathrm{C}$ e 1250 a $1500 \mathrm{~mm}$, respectivamente.

Foram avaliados os clones de taro Macaquinho e Chinês, sob incorporação ao solo de $0 ; 60,120,180$ e $240 \mathrm{~kg} \mathrm{ha}^{-1}$ de uréia (45\% de N), como fatorial $2 \times 5$, no delineamento experimental de blocos casualizados, com três repetições. As parcelas foram compostas por duas linhas de plantas de 2,52 $\mathrm{m}$ de comprimento, arranjadas em um canteiro de 1,5 m de largura total e $1,08 \mathrm{~m}$ de largura útil, com espaçamentos de 0,6 m entre linhas sim- ples, 0,90 m entre linhas duplas e $0,18 \mathrm{~m}$ entre plantas, perfazendo população de 73.260 plantas ha $^{-1}$.

$\mathrm{O}$ experimento foi implantado em solo seco, onde se fez a abertura de sulcos de plantio, com aproximadamente $0,15 \mathrm{~m}$ de largura $\mathrm{x} 0,10 \mathrm{~m}$ de profundidade. As mudas foram rizomas-filho inteiros, separados nos tamanhos grandes, médios e pequenos, com massas médias de 31,78 e 28,64 g; 29,67 e 22,85 g e 18,9 e $16,79 \mathrm{~g}$, para os clones Macaquinho e Chinês, respectivamente. As irrigações foram feitas duas vezes por semana utilizando o sistema de aspersão. Foram realizadas quatro capinas das plantas infestantes com o uso de enxadas. Não foram utilizados agrotóxicos.

A colheita foi efetuada quando mais de $70 \%$ da parte aérea das plantas apresentavam sintomas de senescência, o que induziu à colheita do 'Macaquinho' aos 189 dias após o plantio e a do 'Chinês' aos 232 dias. Após a colheita, foram determinadas as produções de massas fresca e seca dos rizomas totais (rizomas-mãe$\mathrm{RM}+$ rizomas-filho-RF), de RM e de RF comerciais (massa superior a 25,0 g) e RF não-comerciais. Os dados foram submetidos à análise de variância e quando o teste $\mathrm{F}$ utilizado na comparação dos tratamentos foi significativo, a 5\% de probabilidade, aplicou-se o teste de Tukey para diferenciação das médias. Também foram calculadas as prováveis receita e lucro, tomando como base as estimativas de custos de produção, em Dourados-MS, da parte comercial (rizomas-filho comerciais) e da industrialização caseira dos resíduos amídicos (rizomas-mãe + rizomas-filho não-comerciais).

TABELA 1 - Características químicas de amostras do solo da área do experimento, na época da colheita do taro. Dourados-MS, UFMS, 2002-2003.

\begin{tabular}{|c|c|c|c|c|}
\hline \multirow{2}{*}{ Características Químicas* } & \multicolumn{3}{|c|}{ Blocos } & \multirow{2}{*}{ Média } \\
\hline & I & II & III & \\
\hline M.O $\left(\mathrm{g} \mathrm{kg}^{-1}\right)$ & 35,40 & 35,10 & 36,10 & 35,53 \\
\hline pH em água & 6,10 & 5,80 & 6,10 & 6,00 \\
\hline $\mathrm{P}\left(\mathrm{mg} \mathrm{dm}^{-3}\right)$ & 35,40 & 35,70 & 49,60 & 40,23 \\
\hline $\mathrm{K}\left(\mathrm{cmol}_{\mathrm{c}} \mathrm{dm}^{-3}\right)$ & 0,44 & 0,45 & 0,40 & 0,43 \\
\hline $\mathrm{Al}\left(\mathrm{cmol}_{\mathrm{c}} \mathrm{dm}^{-3}\right)$ & 0,00 & 0,00 & 0,00 & 0,0 \\
\hline $\mathrm{Ca}\left(\mathrm{cmol}_{\mathrm{c}} \mathrm{dm}^{-3}\right)$ & 5,00 & 4,20 & 5,20 & 4,80 \\
\hline $\operatorname{Mg}\left(\mathrm{cmol}_{\mathrm{c}} \mathrm{dm}^{-3}\right)$ & 2,80 & 2,10 & 3,00 & 2,63 \\
\hline$\sum$ base $\left(\mathrm{cmol}_{\mathrm{c}} \mathrm{dm}^{-3}\right)$ & 8,24 & 6,75 & 8,60 & 7,86 \\
\hline CTC $\left(\mathrm{cmol}_{\mathrm{c}} \mathrm{dm}^{-3}\right)$ & 13,00 & 12,30 & 12,60 & 12,63 \\
\hline $\mathrm{V}(\%)$ & 64,00 & 55,00 & 68,00 & 62,33 \\
\hline
\end{tabular}

* Análises realizadas no Laboratório de Solos da Embrapa-CPAO, em Dourados-MS. 


\section{RESULTADOS E DISCUSSÃO}

A produção de massa fresca dos rizomas totais foi dependente significativamente dos clones e da adubação com nitrogênio, a produção de rizomas-mãeRM foi dependente dos clones e a produção de rizomas-filho-RF comerciais foi dependente da adubação com nitrogênio. Por meio desses resultados, verificase que as plantas dos clones do taro estudados tiveram grande capacidade de adaptação e de recuperação diante das mudanças no ambiente de cultivo (HEREDIA ZÁRATE, 1988; HEREDIA ZÁRATE et al., 1995, 2000; LARCHER, 2000). As plantas do taro 'Macaquinho' produziram 3,06 (7,88\%) e 3,15 t $\mathrm{ha}^{-1}(42,92 \%)$ a mais no total de rizomas e de RM, respectivamente, com ciclo vegetativo de 43 dias a menos que as do 'Chinês' (Tabela 2), confirmando o exposto por Larcher (2000) de que o padrão de resposta de uma planta e seu potencial específico de adaptação, durante o seu período de crescimento, é característica geneticamente determinada.

Pela produção de massa fresca de RM, em relação ao uso de uréia, constatou-se que as doses dessa fonte de nitrogênio, adicionadas ao solo, não foram suficientes para se obter produções significativamente diferentes (Tabela 3). Esse resultado pode ter relação com o alto teor médio de matéria orgânica do solo onde se instalou o experimento, que foi de $35,53 \mathrm{~g} \mathrm{~kg}^{-1}$ (Ta- bela 1). Isso coincide com resultados de Mesquita Filho et al. (1996), que não obtiveram resposta da mandioquinha-salsa à adubação nitrogenada em um Latossolo Vermelho-Amarelo distrófico, argiloso, e atribuíram o fato à provável alteração da dinâmica do $\mathbf{N}$ pela mineralização da matéria orgânica do solo, em função do preparo, correção e adubação com outros nutrientes, que devem ter induzido a liberação de $\mathbf{N}$ em quantidade suficiente para o suporte da cultura.

A maior produção de massa fresca de RF comerciais com a adição ao solo de 240 e $180 \mathrm{~kg} \mathrm{ha}^{-1}$ de uréia (Tabela 3) deve ter relação com o maior crescimento da parte aérea das plantas (limbos + pecíolos), provavelmente decorrentes do uso da uréia, que é adubo concentrado em $\mathrm{N}$ e que, em geral, induz aumentos no crescimento vegetativo (MALAVOLTA et al., 1989). Quando o elemento for móvel no solo, como é o caso do $\mathbf{N}$, significa que é solúvel em água e a relação do nível dele com a produtividade é, na maioria dos casos, direta ou linear (KIEHL, 1993). Além disso, segundo a hipótese levantada por Heredia Zárate (1988, 1990a, 1990b), após o início do processo natural de senescência das plantas, os rizomas-mãe já devem ter alcançado a maturidade e o máximo crescimento, com conseqüente aumento da translocação dos fotoassimilados dos limbos e dos pecíolos para os RM e desses diretamente para os RF.

TABELA 2 - Produção de massa fresca de rizomas total, mãe e filho (comercial e não-comercial) de plantas de dois clones de taro. Dourados-MS, UFMS, 2002-2003.

Massa Fresca de Rizomas $\left(\mathrm{t} \mathrm{ha}^{-1}\right)$

\begin{tabular}{|c|c|c|c|c|}
\hline \multirow{3}{*}{ Clone } & \multicolumn{4}{|c|}{ Massa Fresca de Rizomas (t ha $\left.{ }^{-1}\right)$} \\
\hline & \multirow{2}{*}{ Total } & \multirow{2}{*}{ Mãe } & \multicolumn{2}{|c|}{ Filho } \\
\hline & & & Comercial & Não-comercial \\
\hline Macaquinho & $41,89 \mathrm{a}$ & 10,49 a & 21,24 & 10,13 \\
\hline Chinês & $38,83 \mathrm{~b}$ & $7,34 \mathrm{~b}$ & 20,07 & 11,43 \\
\hline C.V. $(\%)$ & 21,41 & 30,33 & 24,56 & 25,12 \\
\hline
\end{tabular}

Médias seguidas pelas mesmas letras, nas colunas, não diferem pelo teste $\mathbf{F}$, ao nível de $5 \%$ de probabilidade. 
TABELA 3 - Produção de massa fresca de rizomas total, mãe e filho (comercial e não-comercial) de plantas de taro cultivadas sob cinco doses de uréia. Dourados-MS, UFMS, 2002-2003.

\begin{tabular}{|c|c|c|c|c|}
\hline \multirow{3}{*}{ Dose de uréia } & \multicolumn{4}{|c|}{ Massa fresca de rizomas $\left(\mathrm{tha}^{-1}\right)$} \\
\hline & \multirow{2}{*}{ Total } & \multirow{2}{*}{ Mãe } & \multicolumn{2}{|c|}{ Filho } \\
\hline & & & Comercial & Não-comercial \\
\hline 0 & $38,99 \mathrm{ab}$ & 8,72 & $19,16 \mathrm{~b}$ & 11,11 \\
\hline 60 & $36,42 \mathrm{~b}$ & 9,89 & $15,53 \mathrm{~b}$ & 11,00 \\
\hline 120 & $35,22 \mathrm{~b}$ & 8,19 & $16,91 \quad b$ & 10,12 \\
\hline 180 & $38,10 \mathrm{ab}$ & 8,14 & $19,90 \mathrm{ab}$ & 10,06 \\
\hline 240 & 53,06 a & 9,62 & 31,77 a & 11,67 \\
\hline C.V. (\%) & 21,41 & 30,33 & 24,56 & 25,12 \\
\hline
\end{tabular}

Médias seguidas pelas mesmas letras nas colunas não diferem pelo teste de Tukey, ao nível de $5 \%$ de probabilidade.

A produção de massa seca de rizomas totais foi dependente da interação clones e adubação com uréia, e as doses influenciaram significativamente na produção das plantas do 'Macaquinho' (Tabela 4). Esses resultados vão de encontro ao exposto por Larcher (2000), de que o padrão de resposta de uma planta e seu potencial específico de adaptação, durante o seu período de crescimento, é característica geneticamente determinada. As maiores produções obtidas com 180 e $240 \mathrm{~kg} \mathrm{ha}^{-1}$ de uréia podem ser explicadas pela citação de Ferreira et al. (1993), segundo a qual em vários trabalhos realizados com culturas anuais tem-se demonstrado que nutriente e requerimento de água estão intimamente ligados e que a adubação nitrogenada aumenta a eficiência com que a cultura usa a água disponível. Também pode dever-se, segundo Mesquita Filho et al. (1996), ao fato de os fertilizantes nitrogenados aumentarem a extração de $\mathbf{P}_{\text {total }}$ e $\mathbf{P}_{\text {inorgânico }}$ dos solos, como consequiência da solubilização de $\mathbf{P}_{\text {não extraível }}$ ou do aumento da mineralização de $\mathbf{P}_{\text {orgânico }}$.

As produções de massa seca de RM e das classes de RF variaram significativamente entre clones (Tabela 5), inferindo-se, segundo Embrapa (1996), que a partição dos fotoassimilados é função do genótipo e das relações fonte-dreno Esse fato é confirmado com a menor produção de massa seca de
RF não-comerciais do taro 'Macaquinho' e a maior produção do 'Chinês' (Tabela 5). Além disso, coincide com a variação significativa nas produções de RF comerciais e a não diferenciação significativa das produções de RF não-comerciais em relação às doses de uréia (Tabela 6). Esses resultados podem ser explicados pela capacidade que os sistemas ecológicos têm de se auto-regular com base no equilíbrio das relações de interferência (LARCHER, 2000). Isso porque as plantas dos clones estudados variaram no tempo para alcançar a maturidade e, provavelmente, $o$ máximo crescimento. Com isso, deve ter existido variação da translocação dos fotoassimilados acumulados na parte aérea para o crescimento e aumento de massa dos RM e, posteriormente, desses para os RF (HASHAD et al., 1956; HEREDIA ZÁRATE, 1990a; HEREDIA ZÁRATE et al., 2000).

As maiores receitas e lucros calculados corresponderam à dose de $240 \mathrm{~kg} \mathrm{ha}^{-1}$ de uréia, para os dois clones (Tabela 7). O uso de doses menores mostrou ser economicamente menos rentável para o clone Macaquinho, inclusive em relação à nãoadição de uréia. Em relação ao 'Chinês', os lucros esperados com o uso de 60 a $180 \mathrm{~kg} \mathrm{ha}^{-1}$ de uréia foram praticamente semelhantes e superiores ao tratamento com dose zero de uréia, mas inferiores ao uso de $240 \mathrm{~kg} \mathrm{ha}^{-1}$ de uréia. 
TABELA 4 - Produção de massa seca de rizomas totais $\left(\mathrm{t} \mathrm{ha}^{-1}\right)$ de plantas de dois clones de taro cultivadas sob cinco doses de uréia. Dourados-MS, UFMS, 2002-2003.

\begin{tabular}{lcccccc}
\hline & \multicolumn{5}{c}{ Doses de uréia $\left(\mathbf{k g ~ h a}^{\mathbf{- 1}}\right)$} \\
\cline { 3 - 6 } Clone & $\mathbf{0}$ & $\mathbf{6 0}$ & $\mathbf{1 2 0}$ & $\mathbf{1 8 0}$ & $\mathbf{2 4 0}$ \\
\cline { 3 - 6 } Macaquinho & $8,02 \mathrm{~b}$ & $7,08 \mathrm{~b}$ & $6,30 \mathrm{~b}$ & $8,98 \mathrm{ab}$ & $13,10 \mathrm{a}$ \\
Chinês & $9,71 \mathrm{a}$ & $11,28 \mathrm{a}$ & $10,57 \mathrm{a}$ & $9,96 \mathrm{a}$ & $10,75 \mathrm{a}$ \\
\hline
\end{tabular}

Médias seguidas pelas mesmas letras, nas linhas, não diferem pelo teste de Tukey, ao nível de $5 \%$ de probabilidade.

TABELA 5 - Produção de massa seca de rizomas total, mãe e filho (comercial e não-comercial) de plantas de dois clones de taro. Dourados-MS, UFMS, 2002-2003.

\begin{tabular}{|c|c|c|c|c|}
\hline \multirow{3}{*}{ Clone } & \multicolumn{4}{|c|}{ Massa seca de rizomas $\left(\mathrm{t} \mathrm{ha}^{-1}\right)$} \\
\hline & \multirow{2}{*}{ Total } & \multirow{2}{*}{ Mãe } & \multicolumn{2}{|c|}{ Filho } \\
\hline & & & Comercial & Não-comercial \\
\hline Macaquinho & $8,70 \mathrm{~b}$ & $2,26 \mathrm{a}$ & $4,38 \mathrm{~b}$ & $2,06 \mathrm{~b}$ \\
\hline Chinês & 10,46 a & $1,95 \mathrm{~b}$ & $5,26 \mathrm{a}$ & $3,24 \mathrm{a}$ \\
\hline C.V. $(\%)$ & 16,02 & 20,20 & 24,30 & 43,15 \\
\hline
\end{tabular}

Médias seguidas pelas mesmas letras, nas colunas, não diferem pelo teste $\mathbf{F}$, ao nível de $5 \%$ de probabilidade.

TABELA 6 - Produção de massa seca de rizomas total, mãe e filho (comercial e não-comercial) de plantas de taro cultivadas sob cinco doses de uréia. Dourados-MS, UFMS, 2002-2003.

\begin{tabular}{|c|c|c|c|c|}
\hline \multirow{3}{*}{ Dose de uréia } & \multicolumn{4}{|c|}{ Massa seca de rizomas $\left(\mathrm{t} \mathrm{ha}^{-1}\right)$} \\
\hline & \multirow{2}{*}{ Total } & \multirow{2}{*}{ Mãe } & \multicolumn{2}{|c|}{ Filho } \\
\hline & & & Comercial & Não-comercial \\
\hline 0 & $8,87 \mathrm{ab}$ & 2,11 & $4,13 \mathrm{~b}$ & 2,63 \\
\hline 60 & $9,18 \mathrm{ab}$ & 2,20 & $3,91 \mathrm{~b}$ & 3,08 \\
\hline 120 & $8,44 \mathrm{~b}$ & 1,95 & $4,17 \mathrm{~b}$ & 2,32 \\
\hline 180 & $9,47 \mathrm{ab}$ & 2,04 & $4,85 \mathrm{ab}$ & 2,58 \\
\hline 240 & $11,93 \mathrm{a}$ & 2,23 & $7,05 \mathrm{a}$ & 2,65 \\
\hline C.V. (\%) & 16,02 & 20,20 & 24,30 & 43,15 \\
\hline
\end{tabular}

Médias seguidas pelas mesmas letras, nas colunas, não diferem pelo teste de Tukey, ao nível de $5 \%$ de probabilidade. 
TABELA 7 - Produção, custos, receita e lucro das partes comerciais e do resíduo de plantas de dois clones de taro, cultivadas sob cinco doses de uréia. Dourados-MS, UFMS, 2002-2003.

\begin{tabular}{|c|c|c|c|c|c|c|c|c|}
\hline \multirow{2}{*}{ Clone } & \multirow{2}{*}{$\begin{array}{c}\text { Uréia }^{1} \\
\left(\mathrm{~kg} \mathrm{ha}^{-1}\right)\end{array}$} & \multicolumn{2}{|c|}{ Produção } & \multicolumn{2}{|c|}{ Custo $(\mathbf{R} \$)^{3}$} & \multicolumn{2}{|c|}{ Receita $(\mathbf{R} \$)^{4}$} & \multirow{2}{*}{$\begin{array}{c}\text { Lucro } \\
\text { (R\$) }\end{array}$} \\
\hline & & Forma $^{2}$ & $\left(\mathrm{t} \mathrm{ha} \mathbf{a}^{-1}\right)$ & Parcial & Total & Parcial & Total & \\
\hline M & & Comercial & 21,06 & 1.200 & & 10.530 & & \\
\hline A & 0 & Resíduo & 4,23 & 923,79 & $2.123,79$ & 1.692 & 12.222 & $10.098,21$ \\
\hline $\mathrm{C}$ & & Comercial & 12,16 & 1.248 & & 6.080 & & \\
\hline A & 60 & Resíduo & 4,25 & 928,16 & $2.176,16$ & 1.700 & 7.780 & $5.603,84$ \\
\hline Q & & Comercial & 14,93 & 1.296 & & 7.465 & & \\
\hline $\mathrm{U}$ & 120 & Resíduo & 3,28 & 716,32 & $2.112,32$ & 1.312 & 8.777 & $6.664,68$ \\
\hline I & & Comercial & 21,01 & 1.344 & & 10.505 & & \\
\hline $\mathrm{N}$ & 180 & Resíduo & 4,40 & 960,92 & $2.204,92$ & 1.760 & 12.265 & $10.060,08$ \\
\hline $\mathrm{H}$ & & Comercial & 37,05 & 1.392 & & 18.525 & & \\
\hline \multirow[t]{3}{*}{$\mathrm{O}$} & 240 & Resíduo & 5,43 & $1.185,86$ & $2.577,86$ & 2.172 & 20.697 & $18.119,14$ \\
\hline & & Comercial & 17,27 & 1.200 & & 8.635 & & \\
\hline & 0 & Resíduo & 5,24 & 951,79 & $2.151,79$ & 2.096 & 10.731 & $8.579,21$ \\
\hline $\mathrm{C}$ & & Comercial & 18,91 & 1.248 & & 9.455 & & \\
\hline $\mathrm{H}$ & 60 & Resíduo & 6,30 & $1.144,33$ & $2.392,33$ & 2.520 & 11.975 & $9.582,67$ \\
\hline I & & Comercial & 18,89 & 1.296 & & 9.445 & & \\
\hline $\mathrm{N}$ & 120 & Resíduo & 5,26 & 955,43 & $2.251,43$ & 2.104 & 11.549 & $9.297,57$ \\
\hline$\hat{\mathrm{E}}$ & & Comercial & 18,79 & 1.344 & & 9.395 & & \\
\hline \multirow[t]{3}{*}{$\mathrm{S}$} & 180 & Resíduo & 4,85 & 880,95 & $2.224,95$ & 1.940 & 11.335 & $9.110,05$ \\
\hline & & Comercial & 26,49 & 1.392 & & 13.245 & & \\
\hline & 240 & Resíduo & 4,32 & 784,68 & $2.176,68$ & 1.728 & 14.973 & $12.796,32$ \\
\hline
\end{tabular}

${ }^{1}$ Custo da uréia $=280$ dólares a tonelada. Câmbio do dólar em 15-7-2003 $=\mathbf{R} \$ 2,86$. Preço $=0,80 \mathrm{~kg}$ de uréia ${ }^{2}$ Comercial $=$ Massa fresca de rizomas-filho comerciais. $\quad$ Resíduo $=$ Massas secas de rizomas-mãe + rizomasfilho não-comerciais.

${ }^{3}$ Comercial $=$ Custo médio estimado de $\mathbf{R} \$ \mathbf{1 2 0 0 , 0 0} \mathrm{ha}^{-1}$ pela produtividade média de massa fresca de rizomas-filho comerciais de taro sem adubação nitrogenada. Resíduo = custo médio estimado de $R$ \$ 218,39 e $R \$$ 181,64 para a tonelada de farinha de 'Macaquinho' e de 'Chinês', respectivamente (Divisão de $\mathbf{R} \$ 1.900,00$, custo estimado da farinha produzida $\mathrm{ha}^{-1}$, pela produtividade média de massa seca para cada clone: 8,70 t ha 1 no 'Macaquinho' e 10,46 t ha' ${ }^{-1}$ no 'Chinês')

${ }^{4}$ Preço de massa fresca de rizomas-filhos comerciais, pago ao agricultor $=\mathbf{R} \$ 0,50 \mathbf{~ k g}^{-1}$

Preço estimado de venda da farinha, na fábrica $=R \$ 0,40 \mathrm{~kg}^{-1}$ 


\section{CONCLUSÕES}

O taro 'Macaquinho' pode ser recomendado para o cultivo em Dourados-MS. A utilização de $240 \mathrm{~kg} \mathrm{ha}^{-1}$ de uréia induziu a maior produção e receita financeira nos clones Macaquinho e Chinês.

\section{AGRADECIMENTOS}

Ao CNPq, pelas bolsas concedidas e à FUNDECT-MS, pelo apoio financeiro.

\section{REFERÊNCIAS BIBLIOGRÁFICAS}

ABRAMO, M. A. Taioba, cará e inhame. São Paulo: Ícone, $1990.80 \mathrm{p}$.

CARÁ e inhame. In: ANUÁRIO a granja do ano. São Paulo: Centaurus, 1994. p. 30-35.

CAMPORA, P. S. Importância da adubação na qualidade de tubérculos e raízes. In: SÁ, M. E. de; BUZZETI, S. Importância da adubação na qualidade dos produtos agrícolas. São Paulo: Ícone, 1994. p. 357- 372.

EMPRESA BRASILEIRA DE PESQUISA AGROPECUÁRIA. Recomendações técnicas para o cultivo do milho. 2. ed. Brasília: EMBRAPA-SPI, 1996. $204 \mathrm{p}$.

EPSTEIN, E. Nutrição mineral das plantas: princípios e perspectivas. São Paulo: USP, 1975. 344 p.

FERREIRA, M. E.; CASTELLANE, P. D.; CRUZ, M. C. P. da. Nutrição e adubação de hortaliças. Piracicaba: POTAFOS, 1993. 487 p.

FORNASIERI FILHO, D. A cultura do milho. Jaboticabal: FUNEP, 1992. 273 p.

HASHAD, M. N.; STINO, K. R.; EL-HINNAMY, S. I. Transformation and translocation of carbohidrates in taro plants during growth. Annals of Agricultural Sciences, Cairo, v. 1, n. 1, p. 261-267, 1956.

HEREDIA ZÁRATE, N. A. Curvas de crescimento de inhame (Colocasia esculenta (L.) Schott), considerando cinco populações, em solo seco e alagado. 1988. 95 f. Tese (Doutorado em Fitotecnia) - Universidade Federal de Viçosa, Viçosa, 1988.

HEREDIA ZÁRATE, N. A. Curvas de crescimento de inhame e da variação na composição química e na umi- dade do solo, considerando cinco populações e cinco épocas de preparo do solo. In: ENCONTRO NACIONAL SOBRE A CULTURA DO INHAME, 2., 1989, Dourados. Anais... Campo Grande: UFMS, 1990a. p. 11-42.

HEREDIA ZÁRATE, N. A. Propagação e tratos culturais em inhame (Colocasia esculenta (L.) Schott) cultivado em solo seco. In: ENCONTRO NACIONAL SOBRE A CULTURA DO INHAME, 2., 1989, Dourados. Anais... Campo Grande: UFMS, 1990b. p. 59-96.

HEREDIA ZÁRATE, N. A. Produção de cinco clones de inhame cultivados no pantanal sul-matogrossense. Horticultura Brasileira, Brasília, v. 13, n. 1, p. 38-40, 1995.

HEREDIA ZÁRATE, N. A.; ALVES, S. T.; VIEIRA, M. C.; SUZUKI, M. T. Influência do espaçamento na cultura e na colheita semi-mecanizada de inhame. Horticultura Brasileira, Brasília, v. 13, n. 1, p. 59-60, 1995.

HEREDIA ZÁRATE, N. A.; VIEIRA, M. C.; JORGE, F. D.; GARCIA, A. H. Cará, inhame e mandioquinhasalsa na alimentação de frangos de corte. Revista Cerrados, Campo Grande, v. 2/4, n. 3/8, p. 7-11, 2001.

HEREDIA ZÁRATE, N. A.; VIEIRA, M. C.; LOPES, J. Produção de rizomas de inhame 'Cem/Um' sob nove populações de plantas em Dourados-MS. Ciência e Agrotecnologia, Lavras, v. 24, n. 1, p. 118-123, 2000.

HEREDIA ZÁRATE, N. A.; YAMAGUTI, C. Y. Curvas de crescimento de cinco clones de inhame, em solo "sempre úmido", considerando épocas de colheita, em Dourados-MS. SOBInforma, Curitiba, v. 13, n. 2, p. 23-24, 1994.

KIEHL, E. J. Fertilizantes organominerais. Piracicaba: [s.n.], 1993. 189 p.

LARCHER, W. Ecofisiologia vegetal. Tradução de: Carlos Henrique Britto de Assis Prado. 2. ed. São Carlos: RiMa Artes e Textos, 2000. 531 p.

MALAVOLTA, E.; VITTI, G. C.; OLIVEIRA, S. A. Avaliação do estado nutricional das plantas: princípios e aplicações. Piracicaba: POTAFOS, 1989. 201 p.

MATO GROSSO DO SUL. Secretaria de Planejamento e Coordenação Geral. Atlas Multireferencial. Campo Grande, 1990. 28 p. 
MESQUITA FILHO, M. V. de; SOUZA, A. F.; SILVA, H. R. da; SANTOS, F. F. dos; OLIVEIRA, S. A. de. Adubação nitrogenada e fosfatada para produção de mandioquinha-salsa em latossolo vermelho-amarelo. Horticultura Brasileira, Brasília, v. 14, n. 2, p. 211 215, 1996.

PEREIRA, N. N. C. Sistema de produção do inhame no Estado do Rio de Janeiro. In: ENCONTRO NACIONAL SOBRE A CULTURA DO INHAME, 1., 1987, Viçosa. Anais... Viçosa: UFV, 1994. p. 51.

PLUCKNETT, D. L.; PEÑA, R. S. de la; OBRERO, F. Taro (Colocasia esculenta). Field Crops Abstracts, [S.1.], v. 23, n. 4, p. 413-23, 1970.
PUIATTI, M. Nutrição mineral e cobertura morta na cultura de inhame. In: ENCONTRO NACIONAL SOBRE A CULTURA DO INHAME, 2., 1989, Dourados. Anais... Campo Grande: UFMS, 1990. p. 43-58.

SANTOS, J. N. Sistema de produção de inhame da Região de Inhapim-MG. In: ENCONTRO NACIONAL SOBRE A CULTURA DO INHAME, 1., 1987, Viçosa. Anais... Viçosa: UFV, 1994. p. 4-6.

VIEIRA, M. C. Avaliação do crescimento e da produção de clones e efeito de resíduo orgânico e de fósforo em mandioquinha-salsa no Estado de Mato Grosso do Sul. 1995. 146 f. Tese (Doutorado em Fitotecnia) - Universidade Federal de Viçosa, Viçosa, 1995. 